\title{
Research on Sampling City Design Based on Electronic Map Navigation
}

\author{
Zhang Zhuo \\ Hei He Xue Yuan, Heihe Heilongjiang 164399,China \\ zhangzhuo@163.com
}

Keywords: Electronic map, Multi-stage sampling design, Sampling frame

\begin{abstract}
By lots of practical application and theoretical evidence in investigation of social statistics, the writer designs a multi-stage sampling design which not only is easy to be promoted and implemented, and has low cost and high accuracy, but also is widely applied to the measurement of modern city groups. The method can use the development technique of electronic map to generate good application scalability only with the help of fewer public resources. The paper observes theoretic framework of the method, and introduces the development requirement of electronic map facing auxiliary sample.
\end{abstract}

\section{Background of Problem}

The theoretical development of statistical sampling survey in almost a century makes great contribution for people to knowing the nature. The sampling method plays a leading role in the development of research activities including economic operation, social development and educational entertainment in developed countries, and becomes the most scientific and most important data collection method in modern society.

The research on sampling method is shocked by big data. Many applicators begin exploring the sampling technique. The relationship between sampling technique and big-data method is similar to that between physical shopping and online shopping. Big-data method has high requirement on scientific popularization of human society to completely replace sample technique, which can't be realized in a short time. And it is not realistic to completely abandon the observation on sampling technique. Sampling technology needs to advance with the times. Using modern convenient technical means to improvement sampling mode, improving the efficiency of implementing samples, reducing the cost of samples and promoting feasible techniques is the objective of the modern researchers of statistical method.

By lots of practical application and theoretical evidence in investigation of social statistics, the writer designs a sampling design and data management method assisted with interactive electronic map. And the method not only easy to be promoted and implemented, and has low cost and high accuracy, but also is widely applied to measure groups.

\section{Sampling Plan Design}

In order to be easy for expression, the investigation objectives are all the residents in a city with clear geographic boundary. And the sampling design scheme is explained as follows.

Forms of sampling frame. The sampling frame of the design method consists of three parts, as follows.

Multi-stage design. Sampling design is divided into three stages, in which primary sampling unit is the layer, and secondary sampling unit is the segmented blocks, and the third-stage sampling unit is resident.

The reason why the layer PSU is configured is that nearly all cities form year-ring plan pattern under the long-term urbanization development. Development and expansion from the central zone of the city to the surroundings makes the city form multiple natural loop lines. In the investigation practice, we can find that there is difference between each layer of loop lines, so in the first stage of sampling, according to different natural regions in the development of cities, the sampling is divided into representative layers (PSU). Each PSU is segmented into several blocks (SSU) 
according to natural condition of streets, and then PSU receives proportionate stratified sampling. Table 1 Composition of sampling frame and production table

\begin{tabular}{c|c|l|l}
\hline $\begin{array}{c}\text { Level of sampling } \\
\text { frame }\end{array}$ & \multicolumn{1}{|c|}{ Manifestation } & \multicolumn{1}{|c|}{ Production method } & Application method \\
\hline $\begin{array}{c}\text { Primary sampling } \\
\text { frame }\end{array}$ & $\begin{array}{c}\text { Frame of city region } \\
\text { map }\end{array}$ & $\begin{array}{l}\text { Using the newest electronic } \\
\text { map of city group on Internet }\end{array}$ & $\begin{array}{l}\text { Using electronic map to } \\
\text { index the selected blocks }\end{array}$ \\
\hline $\begin{array}{c}\text { Secondary } \\
\text { sampling frame }\end{array}$ & $\begin{array}{c}\text { Frame of streets and } \\
\text { blocks directory }\end{array}$ & $\begin{array}{l}\text { Using electronic map to divide } \\
\text { natural streets into several } \\
\text { blocks. The blocks are } \\
\text { numbered and enter into the } \\
\text { statistic software to from } \\
\text { electronic sampling frame }\end{array}$ & $\begin{array}{l}\text { The electronic sampling } \\
\text { frames of blocks are } \\
\text { selected randomly to get the } \\
\text { required blocks to be } \\
\text { investigated. }\end{array}$ \\
\hline $\begin{array}{c}\text { Tertiary sampling } \\
\text { frame }\end{array}$ & $\begin{array}{l}\text { Frame of household } \\
\text { number in blocks }\end{array}$ & $\begin{array}{l}\text { investigated are observed, and } \\
\text { the residential buildings and } \\
\text { the residents are numbered. }\end{array}$ & $\begin{array}{l}\text { Random sampling is used to } \\
\text { select the investigated } \\
\text { household from the } \\
\text { selected block to be } \\
\text { investigated. }\end{array}$ \\
\hline
\end{tabular}

In the second stage of sampling, the selected SSU in each PSU needs to be determined. Each SSU forms naturally. The scale of SSU can be controlled in the secondary sampling frame, but there is great difference for scale between SSU. In order to improve the sampling accuracy and make investigation easy to be implemented, Probability-Proportional-to-Size Sampling is used in the second stage. As the estimation and accuracy is easy to be converted, the second-stage sampling finally uses weighting PPS sampling, which means that the residents TSU are selected from the selected SSU.

In the third stage of the sampling, the selected SSU receives on-the-spot investigation and TSU is selected. The investigation content is to number all TSU in SSU to make the tertiary sampling frame. Then, the class interval is achieved by selecting circular systematic sampling. The initiative TSU sample is determined in the tertiary sampling frame, and all TSU samples are selected from circular equivalent sampling.

\section{Design of Interactive Electronic Map System}

In order to enhance the applicability and scalability of sampling design, the writer develops an interactive electronic map system which uses city group measurement as the objective, faces the user of investigation program group, and can assist program design, sampling implementation, data management and initial analysis.

Scale representation of map. According to the requirements of the program, electronic map system design needs to provide multi-scale expressions, as shown in Table 2.

Table 2 Scales of map

\begin{tabular}{l|l|l|l}
\hline Scale level & Scale name & Scale characteristic & Major information \\
\hline Primary & $\begin{array}{l}\text { General universe } \\
\text { scale }\end{array}$ & $\begin{array}{l}\text { The geographic location of } \\
\text { investigation group }\end{array}$ & $\begin{array}{l}\text { Topological structure layer and } \\
\text { major landmark layer of main } \\
\text { streets of cities }\end{array}$ \\
\hline Tertiary & Layer scale & $\begin{array}{l}\text { The geographic location of each } \\
\text { layer }\end{array}$ & $\begin{array}{l}\text { Topological structure layer and } \\
\text { major landmark layer of main } \\
\text { streets in layers. }\end{array}$ \\
\hline Fourth-level & Slock scale & $\begin{array}{l}\text { The geographic location of each } \\
\text { block }\end{array}$ & $\begin{array}{l}\text { Topological structure layer and } \\
\text { major landmark layer of } \\
\text { connected roads in blocks }\end{array}$ \\
\hline
\end{tabular}

The electronic database, measuring scale and icon library of each scale is established and managed hierarchically, and realizes information retrieval, navigation, and visualization application 
of figures. And application links are established between each level of scale.

Interaction design requirements. According to the features of investigation tasks, different interactive functions are realized in each level of electronic map, as shown in Table 3.

Table 3 Interactive functions of each scale

\begin{tabular}{l|l|l}
\hline Scale level & Requirement analysis & Interactive functions \\
\hline Primary & $\begin{array}{l}\text { Determining } \\
\text { investigation }\end{array}$ & $\begin{array}{l}\text { Geographical boundary retouch and landmark information } \\
\text { management }\end{array}$ \\
\hline Secondary & Division of layer & $\begin{array}{l}\text { Layer boundary retouch, estimation of blocks in layers and } \\
\text { landmark information management }\end{array}$ \\
\hline Tertiary & Division of block & $\begin{array}{l}\text { Boundary retouch of blocks, estimation of residents in } \\
\text { blocks, and landmark information management }\end{array}$ \\
\hline Fourth level & $\begin{array}{l}\text { Simulation information of } \\
\text { stair }\end{array}$ & $\begin{array}{l}\text { Floor, number of units, scale of household and range of } \\
\text { users }\end{array}$ \\
\hline
\end{tabular}

Electronic map assisting sampling is different from general electronic map. The implementation effect of basic interactive functions represents auxiliary ability of sampling.

Auxiliary sampling. Auxiliary sampling can be implemented as follows.

(1)The user inputs the number of selected blocks $n$ and the number of households $m$ of each block. If the user hopes to design the total number of samples from the perspective of controlling cost, the total cost is $C$, and the estimation of $c_{0}, c_{1}$ and $c_{2}$ is given. Then, the system outputs $n, m$ and $n m$. After determining the number of samples $n m$, it enters the next step.

(2)According to the determined predefined method of $n$ and $m$, the system selects sample blocks and samples for coding.

(3)The geographical information of sample blocks and samples is stored and is exported by system.

\section{Conclusion}

The sampling design method of the paper is the summary on practice examination. And the method uses the modern comprehensive method assisted with scientific technology, which has good application effect. And the writer hopes it can provide technical help for empirical studies of social science in China. The writer is grateful to the support for the funds of projects. And the application of the design method in different problems is improved.

\section{Acknowledgment}

Supported by Natural Science Foundation of Heilongjiang Province of China (General Program No.A201413)

\section{References}

[1] W.G Cochran, sampling technique, China Statistical Publishing House, 1985:359-363.

[2] KirK M.Wolter, Vairance Estimation, China Statistical Publishing House, 1998.

[3] KishL, sampling investigation, China Statistical Publishing House, 1997:342-348.

[4] Judith T.Lessler, Non-sampling error in investigation, China Statistical Publishing House,1988.

[5] Sharon L.Lohr,Sampling:Design and Analysis, China Statistical Publishing House, 2002.

[6] Jin Yongjin, Analysis on non-sampling error, China Statistical Publishing House, 1996.

[7] Feng Shiyong, Theory and method of sampling survey, China Statistical Publishing House, 1998:156-167.

[8] Tao Ran, Observation on sampling design effect under the condition with the same investigation expense, Statistics Education, 2008(1):21-23.

[9] Qin Huaizhen, Research on theory and practical problems in sampling survey, China Statistical Publishing House, 2008:23-27. 
[10] Jin Yongjin, Application of jackknife method to variance estimation of labor in China, Statistic Research, 2007(1):76-78. 